Article

\title{
Reactive and Regulative Temperament in Relation to Clinical Symptomatology and Personality Disorders in Patients with a Substance Use Disorder
}

\author{
Els Santens ${ }^{1,2, *}$, Geert Dom ${ }^{2,3}$ (D), Eva Dierckx ${ }^{1,4}$ and Laurence Claes ${ }^{2,5}$ (D) \\ 1 Alexian Psychiatric Hospital, 3300 Tienen, Belgium; eva.dierckx@azt.broedersvanliefde.be \\ 2 Faculty of Medicine and Health Sciences, University of Antwerp, 2610 Antwerp, Belgium; \\ geert.dom@uantwerpen.be (G.D.); laurence.claes@uantwerpen.be (L.C.) \\ 3 Multiversum Psychiatric Hospital, 2530 Boechout, Belgium \\ 4 Developmental and Life Span Psychology, Vrije Universiteit Brussel, 1050 Brussels, Belgium \\ 5 Faculty of Psychology and Educational Science, Katholieke Universiteit Leuven, 3000 Leuven, Belgium \\ * Correspondence: els.santens@azt.broedersvanliefde.be
}

check for

updates

Citation: Santens, E.; Dom, G.;

Dierckx, E.; Claes, L. Reactive and Regulative Temperament in Relation to Clinical Symptomatology and Personality Disorders in Patients with a Substance Use Disorder. J. Clin. Med. 2022, 11, 591. https:// doi.org/10.3390/jcm11030591

Academic Editors: Arnt F. A Schellekens and Icro Maremmani

Received: 5 November 2021

Accepted: 20 January 2022

Published: 25 January 2022

Publisher's Note: MDPI stays neutral with regard to jurisdictional claims in published maps and institutional affiliations.

Copyright: (C) 2022 by the authors. Licensee MDPI, Basel, Switzerland. This article is an open access article distributed under the terms and conditions of the Creative Commons Attribution (CC BY) license (https:// creativecommons.org/licenses/by/ $4.0 /)$.

\begin{abstract}
Temperament and personality traits are important factors underlying the vulnerability for both the initiation and continuation of addictive behaviors. We investigated the influence of reactive and regulative temperament and their interaction in relation to clinical symptomatology and personality disorders (PDs) in a sample of 841 inpatients (68.1\% males) with a substance use disorder (SUD). To assess reactive temperament we used the Behavioral Inhibition and Behavioral Activation Scales (BISBAS) and to assess regulative temperament we used the Effortful Control Scale. Clinical symptomatology and personality traits were measured by means of the Symptom Checklist-90 (SCL-90) and the Assessment of ADP-IV Personality Disorders (ADP-IV). Hierarchical regression analyses showed that both, clinical symptomatology and PDs were related to low levels of effortful control (EC). None of the two-way interactions (BIS $\times \mathrm{EC}$, BAS $\times \mathrm{EC}$ ) however were significantly related to psychopathology. Current findings highlight the role of effortful control (EC) in the expression of psychopathology in an adult sample of inpatients with SUD. Therapeutic interventions aiming at strengthening EC can possibly result in better treatment outcomes for both the addiction and the comorbid psychopathology.
\end{abstract}

Keywords: substance use disorders; effortful control; behavioral inhibition; behavioral activation; clinical symptoms; personality disorders

\section{Introduction}

SUDs are highly prevalent disorders with reported lifetime prevalence rates of any substance abuse or dependence between $10-20 \%$ in the general population $[1,2]$ and constitute a major public health problem [3]. SUDs are heterogeneous disorders characterized by compulsive drug seeking/taking, the inability to limit intake and the experience of negative affect and withdrawal symptoms in absence of substances [4]. A vulnerability to disinhibition or a lack of self-regulation seems to be a core risk factor associated with both the initiation and continuation of substance use disorders [5]. SUDs frequently cooccur with other psychiatric disorders such as mood and anxiety disorders [6], personality disorders (PDs) and psychotic disorders [7,8].

Self-regulation or EC refers to the ability to regulate behaviors, emotions and cognitions. In a review by Santens et al. (2020) EC is considered as a transdiagnostic dimension underlying externalizing (e.g., SUDs, ADHD) as well as internalizing (e.g., anxiety and mood disorders) psychopathology [9]. EC is a regulative dimension of temperament that involves attentional control, inhibitory control and activation control, and reflects self-regulation abilities that develop later in life parallel with the maturation of the prefrontal cortex and refers to top-down control [10]. According to the dual pathways model, 
psychopathology arises from an imbalance between two complementary neurobiological systems: (1) the impulsive system or the bottom-up reactivity in terms of behavioral inhibition (BIS) and behavioral activation (BAS) system and (2) the reflective system or top-down regulation in terms of EC [11-13]. Vulnerability theories of psychopathology emphasize the role of self-regulation or EC which may moderate the association between temperamental (BISBAS) reactivity and psychopathology [8,9,14-18].

The reactive dimensions of temperament are described in Gray's Reinforcement Sensitivity Theory (RST), in which BAS refers to sensitivity to reward and BIS to sensitivity to punishment [13]. These reactive temperamental traits defined by the RST refer to bottom-up processes which can already be observed in early childhood. Overactivation of BIS or BAS reactivity can be related to different forms of psychopathology. People with high BAS activation tend to be more impulsive and extraverted, whereas higher BIS activation results in higher proneness to anxiety and is associated with Neuroticism [19-21]. Additionally, internalizing problems (e.g., anxiety and mood disorders) are more related to an overactive BIS, whereas externalizing problems (e.g., SUDs) are related to an overactive BAS and an underactive BIS which fails to inhibit inappropriate behaviour that was initiated by BAS [22,23]. Clinical research points out that individuals with low levels of EC are at increased risk for multiple types of psychopathologies see [8]. In terms of reactive and regulative temperament, EC often moderates the relationship between BISBAS reactivity and psychopathology: internalizing disorders (e.g., anxiety and mood disorders) more often seem to be characterized by high levels of BIS and low levels of EC, whereas externalizing disorders (e.g., SUDs, ADHD) by high levels of BAS and low levels of EC $[8,16]$.

In terms of both reactive and regulative temperament, we expect SUDs to be especially characterized by high levels of BAS and low levels of EC. In the literature we indeed found BAS sensitivity in particular to be linked to several types of substance abuse and acting as a predictor of reactivity to alcohol cues, cue-elicited craving and positive alcohol expectancies [24-26].

Additionally, we know that a lack of self-regulatory processes (low EC) is also a core risk factor for both the initiation and continuation of SUDs [5,27]. Several studies examined the role of EC in SUDs in which low EC was related to SUD at all stages of addiction [28,29]. High EC was linked to less substance use and a lower drinking frequency [30,31]. Chronic use of substances is known to undermine the efficiency of control networks, including dorsolateral prefrontal cortex, ventromedial prefrontal cortex, and anterior cingulate cortex regions, weakening the capacity for self-regulation when exposure to drug cues occurs and worsens the cycle of addiction [30,32].

Importantly previous research in a large clinical sample of SUD patients highlighted the role of BIS as well. It was found that the cluster of SUD patients characterized by high BIS and low EC had the highest levels of psychopathology on all clinical symptoms (especially on internalizing symptoms: depression and anxiety) and more cluster B and C PDs as compared with the cluster of SUD patients characterized by high BAS and low EC [33].

Of importance, these temperamental factors are implicated in a broad spectrum of psychiatric disorders [8]. A sizeable number of patients with SUD have comorbid psychopathologies such as mood and anxiety disorders and PDs (especially the antisocial PD (ASPD) and the borderline PD (BPD) [6,34-36]. Further, psychotic disorders and schizophrenia are also highly comorbid with SUDs [1-3]. We will further elucidate the role of BIS, BAS and EC underlying the comorbid mood and anxiety disorders and PDs in a large sample of patients with SUD.

Mood and anxiety disorders are the most prevalent clinical disorders in the general population [37]. The report of EMDCCA on comorbidity of SUD and mental disorders in Europe (2015) reports that (a) depression with SUD is the most common comorbidity, with prevalence rates ranging from $12 \%$ to $80 \%$, depending on the characteristics of the sample (e.g., clinical versus non-clinical samples, diagnostic criteria used), and that (b) anxiety disorders are also commonly seen in association with SUD, with prevalence rates as high 
as 35\%. However, the causal relationships between anxiety disorders and SUD (selfmedication theories, substance-induced anxiety) are not clearly established and also depend on the specific combination of drugs (e.g., cocaine, cannabis) and anxiety disorders (e.g., post-traumatic stress disorder, panic disorder) [38].

Mood and anxiety disorders are marked by high levels of BIS, low levels of BAS (for depression) and low levels of EC [18,39-41]. High BIS is assumed to be a vulnerability factor to internalizing pathology [1] and underlies the personality dimension of anxiety. Additionally, research linked depression to a reward hyposensitivity (low BAS) resulting in a lower approach motivation [18]. Furthermore, behavioral activation interventions have played an important role in treating depressive episodes and reducing relapses [42]. Previous results also indicated that low BAS sensitivity is not only a potential marker of vulnerability to depression but also may be useful in predicting the course of the depressive disorder [18,42].

PDs are defined as enduring and maladaptive patterns of perceiving, thinking about, relating to and interacting with people. PDs can be grouped into three clusters: Cluster $\mathrm{A}$ is characterized by eccentric/odd behaviour, Cluster B by erratic/dramatic behaviour and Cluster $C$ by anxious/avoidant behaviour [43]. PDs research shows that cluster B PDs were characterized by high BAS, cluster C PDs by high BIS and cluster A PDs by a mixed pattern of BIS/BAS [18]. Furthermore, several studies have described impairments in self-regulation capacities (low EC) in PDs [44-46].

PDs and SUDs commonly co-occur with prevalence rates of PDs in patients with SUD ranging from $24 \%$ to $90 \%$ depending on the sample characteristics and settings [47]. Concerning the high co-occurrence between SUDS and BPD and ASPD, emotion dysregulation as well as impulsivity play an important role in both disorders [48].

There is growing interest in the possible transdiagnostic role of EC in both SUDs and in their comorbid disorders. It would thus be of clinical interest to investigate the influence of reactive (BIS/BAS) and regulative temperament (EC) and their interaction in a large sample of SUD patients in relation to clinical symptomatology and personality disorders providing new insights in understanding the role of temperamental factors developing co-morbid psychological problems with SUDs. Therefore, in the current study, we want to expand existing research by examining whether effortful control moderates the influence of reactive (BIS/BAS) temperament in relation to clinical symptomatology and PDs in a large sample of adult inpatient with SUDs.

Based on the current theoretical perspective that the interaction between certain reactive temperament traits (BIS/BAS) and self-regulatory capacities (EC) may increase or decrease the risk for psychopathology [14-18], we expect to find (a) concerning clinical symptomatology that internalizing symptoms are related to high levels of BIS and externalizing symptoms to be related to high levels of BAS in combination with low EC $[18,30]$ and (b) concerning PDs we expect Cluster B PDs to be related to high levels of BAS and Cluster C PDs to high levels of BIS $[6,18,33-36,44,46]$ in combination with low EC.

\section{Materials and Methods}

\subsection{Participants and Procedure}

The study included 841 adult Caucasian inpatients (68.1\% males, $38.8 \%$ females and $0.1 \%$ gender unknown) consecutively admitted from April 2015 till June 2020 at the treatment unit for addiction of the Alexian Psychiatric Hospital, Tienen, Belgium. This unit provides a residential cognitive behavioral therapy program for patients with a SUD.

In this sample, 177 (21\%) patients only used alcohol, 583 (69.2\%) used alcohol and another substance and $57(6.8 \%)$ patients used another substance, such as amphetamine, cocaine, cannabis, benzodiazepines, and opioid analgetics (Table 1). The SUDs most frequently seen at our treatment service are alcohol use disorders $(21.5 \%)$, alcohol use disorder and sedative, hypnotic and anxiolytic use disorder (28.8\%) and polysubstance use disorder ( $\geq 3$ substances) (31.9\%). Cocaine Use Disorder accounts for $1.2 \%$, Cannabis 
Use Disorder for $0.6 \%$ and Sedative, Hypnotic and Anxiolytic Use Disorder for 3.1\%, see Supplementary Materials Table S1.

Table 1. Type of Substance Used and Gender.

\begin{tabular}{ccccc}
\hline & Alcohol & Alcohol and Other Substance & Other Substance & Total \\
\hline Male & 121 & 393 & 36 & 552 \\
Female & 56 & 190 & 19 & 265 \\
Total & 177 & 583 & 57 & 817 \\
\hline
\end{tabular}

Experienced psychiatrists assessed the patients by means of the criteria of the Diagnostic and Statistical Manual of Mental Disorders, Fifth Edition (DSM-5, APA, 2013) for SUDs. The mean age of the participants was 42.86 years $(S D=11.74$, range: $17-71$ years). The self-report questionnaires were administered after detoxification during the second week of admission by means of a computer on the ward. All patients signed an informed consent form before participating in the study.

\subsection{Measures}

2.2.1. Behavioral Inhibition System (BAS) and Behavioral Activation System (BAS) Scales (BIS/BAS)

The BIS/BAS scales is a self-report questionnaire consisting of 24 items which are rated on a 4-point Likert scale ranging from ' $1=$ I strongly agree' to ' $4=$ I strongly disagree' which assess the reactivity of the BIS and BAS systems [13]. Cronbach's alpha coefficient of the BIS scale is 0.79 and of the BAS total scale is 0.85 representing acceptable internal consistency in the present sample.

\subsubsection{Adult Temperament Questionnaire Short Form (ATQ-ECS)}

The Effortful Control Scale of the ATQ is a self-report scale consisting of 19 items which are rated on a 7-point Likert scale from ' $1=$ I entirely agree' to ' $7=$ I entirely disagree', which measures an individual's regulatory capacity [49]. The ECS is found to be a reliable measure with good internal consistency and construct validity [50]. The EC total score demonstrated acceptable internal consistency $(\alpha=0.81)$.

\subsubsection{Symptom-Checklist-90-Revised (SCL-90-R, Dutch Version)}

The SCL-90-R is a widely used self-report questionnaire for measuring a range of psychological and psychiatric symptoms consisting of 90 items which are rated on a 5-point Likert scale ranging from ' $1=$ not at all' to ' $5=$ extremely true". It involves nine primary symptom dimensions: depression (DEP), anxiety (ANX), agoraphobia (AGO), somatization (SOM), insufficiency of thought and behavior (IN), hostility (HOS), sleeping problems (SLE), distrust and interpersonal sensitivity (DIS) experienced in the past 7 days [51]. In the present study, Cronbach's alphas are the following: DEP $=0.93, \mathrm{ANX}=0.89, \mathrm{AGO}=0.84$, $\mathrm{SOM}=0.84, \mathrm{INS}=0.84, \mathrm{SEN}=0.90, \mathrm{HOS}=0.79, \mathrm{DIS}=0.78$ representing acceptable internal consistency. Several studies have shown high sensitivity and moderate specificity for the SCL-90-R when used as a screening instrument for mental disorders in SUD patients [52].

\subsubsection{Assessment of DSM-IV Personality Disorders (ADP-IV)}

The ADP-IV consists of 94 items which assesses the risk for 10 DSM-IV PDs [53]. The items are rated on a 7-point Likert scale (trait score) ranging from ' $1=$ totally applicable' to '7 = entirely false'. Summing the scores on the "trait" items for their corresponding scale results in dimensional PD scales.

In the present sample Cronbach's alphas of the ADP-IV dimensional scales range from 0.64 (Schizotypal PD) till 0.86 (Avoidant PD) representing marginally acceptable to acceptable internal consistency coefficients. 


\subsubsection{Drug Use Screening Inventory-Revised (DUSI-R)}

The DUSI-R is a self-report questionnaire which assesses 20 types of substance used the past three months. We divided them into three categories as follows: alcohol use, alcohol use and another substance and use of other substances [54].

\subsection{Statistical Analyses}

Statistical analyses were conducted by means of SPSS Statistics 26 . We performed a series of hierarchical regression analyses with the SCL-90 clinical symptom subscales and the ADP-IV-dimensional PD scores as dependent variables and age, gender (step 1), the main effects of BIS, BAS and EC (step 2) and the two-way interactions (BIS $\times$ EC, BAS $\times$ EC) (step 3) as predictors. The BIS $\times$ BAS interaction was not included because we were particularly interested in the interaction of both BIS/BAS and EC. To compute interaction terms, the independent variables were first standardized.

\section{Results}

\subsection{Characteristics of the Sample}

In this sample, 177 (21\%) patients only used alcohol, 583 (69.2\%) used alcohol and another substance and $57(6.8 \%)$ patients used another substance, such as amphetamine, cocaine, cannabis, benzodiazepines, and opioid analgetics (Table 1 and Supplementary Materials Table S1).

Tables 1 and 2 set out the characteristics of the sample.

Table 2. Descriptive statistics of EC, BIS and BAS for the total sample.

\begin{tabular}{cccccc}
\hline & $\mathbf{N}$ & Minimum & Maximum & M & (SD) \\
\hline Leeftijd & 841 & 17 & 71 & 42.86 & $(11.74)$ \\
ECtot & 800 & 1.68 & 6.53 & 4.31 & $(0.82)$ \\
BIS & 835 & 7.00 & 28.00 & 20.93 & $(4.09)$ \\
BAStot & 835 & 16.00 & 52.00 & 36.51 & $(6.54)$ \\
\hline
\end{tabular}

EC = Effortful Control; BIS = Behavioral Inhibition System; BAS = Behavioral Activation System .

3.2. Influence of Reactive and Regulative Temperamental Aspects and Their Interaction in Relation to Clinical Symptomatology in Inpatients with SUD

The results of the hierarchical regression analyses with the SCL-90 symptoms scales as dependent variables are displayed in Table 3.

The results clearly showed that most of the clinical symptoms (anxiety, depression, obsessive compulsive disorder, interpersonal sensitivity, and the total score) were significantly related to high levels of BIS reactivity and low levels of EC. Sleep problems and somatic complaints were related to female gender and low EC; whereas hostility was associated with a younger age and low EC. None of the two-way interactions $(\mathrm{BIS} \times \mathrm{EC}, \mathrm{BAS} \times \mathrm{EC})$ were significantly related to clinical symptomatology in patients with SUD.

\subsection{Influence of Reactive and Regulative Temperamental Aspects and Their Interaction in Relation} to PDs in Inpatients with SUD

The results of the hierarchical regression analyses with the dimensional ADP-IV as dependent variables are displayed in Table 4.

All PDs were related to low levels of EC.

Further, Cluster B PDs were related to high levels of BAS reactivity for the narcissistic and histrionic PD and cluster C PDs were associated with high levels of BIS reactivity. None of the two-way interaction terms $(\mathrm{BIS} \times \mathrm{EC}, \mathrm{BAS} \times \mathrm{EC})$ were significantly related to PDs in inpatients with SUD. 
Table 3. Hierarchical regression analyses with SCL-90 symptoms scales as dependent variables.

\begin{tabular}{|c|c|c|c|c|c|c|c|c|c|c|}
\hline & AGO & ANX & DEP & HOS & IN & PSYCH & DIS & SLE & SOM & SCL_TOT \\
\hline & $\beta$ & $\beta$ & $\beta$ & $\beta$ & $\beta$ & $\beta$ & $\beta$ & $\beta$ & $\beta$ & $\beta$ \\
\hline $\begin{array}{c}\text { GENDER } \\
\text { AGE }\end{array}$ & $\begin{array}{c}-0.050 \\
0.012 \\
\mathrm{R}^{2}=0.00\end{array}$ & $\begin{array}{c}-0.072 * \\
0.046 \\
\mathrm{R}^{2}=0.01 *\end{array}$ & $\begin{array}{c}-0.072 * \\
0.031 \\
\mathrm{R}^{2}=0.01\end{array}$ & $\begin{array}{c}-0.091 * \\
-0.099^{* *} \\
\mathrm{R}^{2}=0.02 * *\end{array}$ & $\begin{array}{c}-0.034 \\
0.017 \\
\mathrm{R}^{2}=0.00\end{array}$ & $\begin{array}{c}-0.042 \\
0.024 \\
\mathrm{R}^{2}=0.00\end{array}$ & $\begin{array}{c}-0.029 \\
-0.006 \\
\mathrm{R}^{2}=0.00\end{array}$ & $\begin{array}{c}-0.014 \\
-0.016 \\
\mathrm{R}^{2}=0.01\end{array}$ & $\begin{array}{c}-0.060 \\
0.096 * * \\
\mathrm{R}^{2}=0.01^{* *}\end{array}$ & $\begin{array}{c}-0.072 * \\
0.025 \\
\mathrm{R}^{2}=0.006\end{array}$ \\
\hline $\begin{array}{c}\text { GENDER } \\
\text { AGE } \\
\text { EC } \\
\text { BIS } \\
\text { BAS }\end{array}$ & $\begin{array}{c}0.005 \\
0.027 \\
-0.344^{* * *} \\
0.079^{*} \\
-0.013 \\
\mathrm{R}^{2}=0.13^{* * *}\end{array}$ & $\begin{array}{c}-0.008 \\
0.069^{*} \\
-0.374^{* * *} \\
0.098^{* *} \\
0.000 \\
\mathrm{R}^{2}=0.16^{* * *}\end{array}$ & $\begin{array}{c}0.001 \\
0.048 \\
-0.337^{* * *} \\
0.137^{* * *} \\
-0.034^{-0} \\
\mathrm{R}^{2}=0.14^{* * *}\end{array}$ & $\begin{array}{c}-0.052 \\
-0.092^{* *} \\
-0.424^{* * *} \\
0.003^{* *} \\
-0.008^{* * *} \\
\mathrm{R}^{2}=0.19^{* *}\end{array}$ & $\begin{array}{c}0.040 \\
0.043 \\
-0.436^{* * *} \\
0.115^{* * *} \\
-0.004 \\
\mathrm{R}^{2}=0.21^{* * *}\end{array}$ & $\begin{array}{c}0.025 \\
0.052 \\
-0.421^{* * *} \\
0.097^{* *} \\
0.013 \\
\mathrm{R}^{2}=0.19^{* * *}\end{array}$ & $\begin{array}{c}0.032 \\
0.016 \\
-0.373^{* * *} \\
0.090^{*} \\
-0.002 \\
\mathrm{R}^{2}=0.15^{* * *}\end{array}$ & $\begin{array}{c}-0.087^{*} \\
-0.018 \\
-0.153 * * * \\
0.041 \\
-0.035 \\
\mathrm{R}^{2}=0.04^{* * *}\end{array}$ & $\begin{array}{c}-0.006 \\
0.103^{* *} \\
-0.229^{* * *} \\
0.105 \\
-0.046 \\
\mathrm{R}^{2}=0.08\end{array}$ & $\begin{array}{c}0.004 \\
0.047 \\
-0.430^{* * *} \\
0.121^{* * *} \\
-0.019 \\
\mathrm{R}^{2}=0.21^{* * *}\end{array}$ \\
\hline $\begin{array}{c}\text { GENDER } \\
\text { AGE } \\
\text { EC } \\
\text { BIS } \\
\text { BAS } \\
\text { BIS } \times \text { EC } \\
\text { BAS } \times \text { EC }\end{array}$ & $\begin{array}{c}0.006 \\
0.027 \\
-0.345 * * * \\
0.080 * \\
-0.013 \\
-0.046 \\
-0.005 \\
\mathrm{R}^{2}=0.13 \text { *** }\end{array}$ & $\begin{array}{c}-0.007 \\
0.067^{*} \\
-0.374^{* * *} \\
0.098^{* *} \\
-0.001 \\
-0.001 \\
0.040 \\
\mathrm{R}^{2}=0.16^{* * *}\end{array}$ & $\begin{array}{c}0.001 \\
0.047 \\
-0.337^{* * *} \\
0.136^{* * *} \\
-0.034 \\
0.009 \\
0.022 \\
\mathrm{R}^{2}=0.1^{* * *}\end{array}$ & $\begin{array}{c}-0.053 \\
-0.091^{* *} \\
-0.423^{* * *} \\
0.003^{* * *} \\
-0.008 \\
0.016 \\
-0.020 \\
\mathrm{R}^{2}=0.19^{* * *}\end{array}$ & $\begin{array}{c}0.040 \\
0.043 \\
-0.436^{* * *} \\
0.015^{* * *} \\
-0.004 \\
0.010 \\
0.014 \\
\mathrm{R}^{2}=0.21^{* * *}\end{array}$ & $\begin{array}{c}0.026 \\
0.051 \\
-0.421^{* * *} \\
0.097^{* *} \\
0.013 \\
-0.012 \\
0.019 \\
\mathrm{R}^{2}=0.19 * * *\end{array}$ & $\begin{array}{c}0.032 \\
0.015 \\
-0.373 * * * \\
0.089 * \\
-0.002 \\
0.008 \\
0.004 \\
\mathrm{R}^{2}=0.15^{* * *}\end{array}$ & $\begin{array}{c}-0.087 * \\
-0.018 \\
-0.153 * * * \\
0.040 \\
-0.036 \\
0.030 \\
0.016 \\
\mathrm{R}^{2}=0.04 * * *\end{array}$ & $\begin{array}{c}-0.004 \\
0.100^{* *} \\
-0.229^{* * *} \\
0.104^{* *} \\
-0.046 \\
-0.008 \\
0.072 \\
\mathrm{R}^{2}=0.08^{* * *}\end{array}$ & $\begin{array}{c}0.005 \\
0.046 \\
-0.430 * * * \\
0.120 * * * \\
-0.019 \\
0.002 \\
0.026 \\
\mathrm{R}^{2}=0.21^{* * *}\end{array}$ \\
\hline
\end{tabular}

AGO = agoraphobia; ANX = anxiety; DEP = depression; HOS = hostility; IN = insufficiency of thought and behavior; PSCYH = psychoticism dimension; DIS = distrust and interpersonal sensitivity; SLE = sleeping problems; $\mathrm{SOM}=$ somatization problems. ${ }^{*} p<0.05,{ }^{* *} p<0.01,{ }^{* * *} p<0.001$.

Table 4. Hierarchical regression analyses with ADP-IV PD scores as dependent variables.

\begin{tabular}{|c|c|c|c|c|c|c|c|c|c|c|}
\hline & \multicolumn{3}{|c|}{ Cluster A PDs } & \multicolumn{4}{|c|}{ Cluster B PDs } & \multicolumn{3}{|c|}{ Cluster C PDs } \\
\hline & PAR & SZ & ST & AS & BDL & HIS & NARC & AV & DEP & OC \\
\hline & $\beta$ & $\beta$ & $\beta$ & $\beta$ & $\beta$ & $\beta$ & $\beta$ & $\beta$ & $\beta$ & $\beta$ \\
\hline $\begin{array}{c}\text { GENDER } \\
\text { AGE }\end{array}$ & $\begin{array}{c}-0.056 \\
-0.095 * * \\
\mathrm{R}^{2}=0.01 *\end{array}$ & $\begin{array}{c}0.015 \\
-0.037 \\
\mathrm{R}^{2}=0.00\end{array}$ & $\begin{array}{c}-0.040 \\
-0.049 \\
\mathrm{R}^{2}=0.00\end{array}$ & $\begin{array}{c}-0.053 \\
-0.114 * * \\
\mathrm{R}^{2}=0.01 *\end{array}$ & $\begin{array}{c}-0.117 * * * \\
-0.073 * \\
\mathrm{R}^{2}=0.02 *\end{array}$ & $\begin{array}{c}-0.089 * \\
-0.084^{*} \\
\mathrm{R}^{2}=0.01^{* *}\end{array}$ & $\begin{array}{c}-0.036 \\
-0.079 * \\
\mathrm{R}^{2}=0.01\end{array}$ & $\begin{array}{c}-0.030 \\
-0.023 \\
\mathrm{R}^{2}=0.00\end{array}$ & $\begin{array}{c}-0.075^{*} \\
-0.017 \\
\mathrm{R}^{2}=0.01\end{array}$ & $\begin{array}{c}-0.063 \\
-0.053 \\
\mathrm{R}^{2}=0.01\end{array}$ \\
\hline $\begin{array}{c}\text { GENDER } \\
\text { AGE } \\
\text { EC } \\
\text { BIS } \\
\text { BAS }\end{array}$ & $\begin{array}{c}-0.027 \\
-0.073^{*} \\
-0.0335^{* * *} \\
0.000 \\
0.048 \\
\mathrm{R}^{2}=0.14^{* * * a}\end{array}$ & $\begin{array}{c}0.052 \\
-0.028 \\
-0.156^{* * *} \\
0.076^{*} \\
-0.017 \\
\mathrm{R}^{2}=0.03^{* * *}\end{array}$ & $\begin{array}{c}0.007 \\
-0.032 \\
-0.421^{* * *} \\
0.036 \\
0.011 \\
\mathrm{R}^{2}=0.18^{* * * a}\end{array}$ & $\begin{array}{c}-0.021 \\
-0.092 * * \\
-0.539 * * * \\
-0.041 \\
0.054 \\
\mathrm{R}^{2}=0.30 * * *\end{array}$ & $\begin{array}{c}-0.060^{*} \\
-0.046 \\
-0.548^{* * *} \\
0.036 \\
0.033 \\
\mathrm{R}^{2}=0.32 \text { *** }\end{array}$ & $\begin{array}{c}-0.030 \\
-0.046 \\
-0.532^{* * *} \\
0.051 \\
0.064^{*} \\
\mathrm{R}^{2}=0.30^{* * *}\end{array}$ & $\begin{array}{c}-0.017 \\
-0.049 \\
-0.366^{* * *} \\
-0.032 \\
0.088^{*} \\
\mathrm{R}^{2}=0.15^{* * *}\end{array}$ & $\begin{array}{c}0.030 \\
-0.008 \\
-0.386^{* * *} \\
0.086^{*} \\
-0.020 \\
\mathrm{R}^{2}=0.16^{* * *}\end{array}$ & $\begin{array}{c}-0.013 \\
0.006 \\
-0.469^{* * *} \\
0.071^{*} \\
0.010 \\
\mathrm{R}^{2}=0.23^{* * *}\end{array}$ & $\begin{array}{c}-0.017 \\
-0.034 \\
-0.200^{* * *} \\
0.093^{* *} \\
0.003 \\
\mathrm{R}^{2}=0.06^{* * *}\end{array}$ \\
\hline $\begin{array}{c}\text { GENDER } \\
\text { AGE } \\
\text { EC } \\
\text { BIS } \\
\text { BAS } \\
\text { BIS } \times \text { EC } \\
\text { BAS } \times \text { EC }\end{array}$ & $\begin{array}{c}-0.029 \\
-0.072 * \\
-0.035 * * * \\
0.000 \\
0.049 \\
0.011 \\
-0.035 \\
\mathrm{R}^{2}=0.14^{* * *}\end{array}$ & $\begin{array}{c}0.055 \\
-0.029 \\
-0.158^{* * *} \\
0.077^{*} \\
-0.017 \\
-0.069^{*} \\
0.028 \\
\mathrm{R}^{2}=0.04^{* * *}\end{array}$ & $\begin{array}{c}0.009 \\
-0.033 \\
-0.422^{* * *} \\
0.037 \\
0.011 \\
-0.044 \\
0.014 \\
\mathrm{R}^{2}=0.1^{* * *}\end{array}$ & $\begin{array}{c}-0.021 \\
-0.092 * * \\
-0.539 * * \\
-0.040 \\
0.055 \\
-0.014 \\
-0.016 \\
\mathrm{R}^{2}=0.30^{* * *}\end{array}$ & $\begin{array}{c}-0.061 * \\
-0.045 \\
-0.547^{* * *} \\
0.035 \\
0.033 \\
0.031 \\
-0.013 \\
\mathrm{R}^{2}=0.32 * * *\end{array}$ & $\begin{array}{c}-0.029 \\
-0.047 \\
-0.533^{* * *} \\
0.052 \\
0.084^{*} \\
-0.032 \\
0.010 \\
\mathrm{R}^{2}=0.30 * * *\end{array}$ & $\begin{array}{c}-0.016 \\
-0.049 \\
-0.366^{* * *} \\
-0.030 \\
0.089 * * \\
-0.044 \\
-0.010 \\
\mathrm{R}^{2}=0.15^{* * *}\end{array}$ & $\begin{array}{c}0.029 \\
-0.008 \\
-0.386^{* * *} \\
0.086^{* *} \\
-0.020 \\
0.012 \\
-0.023 \\
\mathrm{R}^{2}=0.16^{* * *}\end{array}$ & $\begin{array}{c}-0.015 \\
0.007 \\
-0.468^{* * *} \\
0.070^{* *} \\
0.010 \\
0.034 \\
-0.014 \\
\mathrm{R}^{2}=0.23^{* * *}\end{array}$ & $\begin{array}{c}-0.018 \\
-0.036 \\
-0.199 * * * \\
0.091^{* *} \\
0.002 \\
0.049 \\
0.046 \\
\mathrm{R}^{2}=0.06^{* * *}\end{array}$ \\
\hline
\end{tabular}

PAR, paranoid PD; SZ, schizoid PD; ST, schizotypal PD; AS, antisocial PD; BDL, borderline PD; HIS, histrionic PD; NARC, narcissistic PD; AV, avoidant PD: DEP, dependent PD; OC, obsessive compulsive PD. ${ }^{a}$ A significant increase in $\mathrm{R}^{2}$ compared to prior step. ${ }^{*} p<0.05,{ }^{* *} p<0.01,{ }^{* * *} p<0.001$.

\section{Discussion}

In the present study, we investigated the influence of reactive (BIS/BAS) and regulative (EC) temperament and their interaction on clinical symptomatology and PDs in adult inpatients with SUD. In our sample most patients had an AUD (21\%) or used alcohol in combination with other substance(s) (68.2\%).

Concerning clinical symptomatology, the results clearly showed the most of clinical symptoms (anxiety, depression, OCD, interpersonal sensitivity, and the total score) were associated with high levels of BIS reactivity and low levels of EC. These findings are in line with the existing literature stating that internalizing disorders (e.g., anxiety and mood disorders) are characterized by low levels of EC and high levels of BIS $[8,18,33]$. In SUDS there is a high comorbidity of mood and anxiety disorders [6,34,55]. A meta-analysis indicated the strongest associations between illicit drug use disorder and major depression, followed by illicit drug use and any anxiety disorder, alcohol use disorders and major 
depression and alcohol use disorders and any anxiety disorder diagnoses based on lifetime or 12-month prevalence [56].

Drinking to cope with anxiety and negative affectivity is a potent marker for current and future problems with alcohol in high BIS individuals and may point to negative reinforcement drinking $[5,57,58]$. Research shows evidence for the overlapping neurobiology of negative affect and SUD. The negative affect, associated with withdrawal is linked with a diminished activation in the reward circuitry and activation of the stress neurotransmitters in the extended amygdala. The amygdala is also connected to brain areas involved in executive function (medial prefrontal cortex), emotion regulation, stress reactivity (paraventricular hypothalamus and locus coeruleus), and reward processing (nucleus accumbens shell and ventral tegmental area $[55,59,60]$. Research also shows that chronic alcohol use results in neuroadaptations to the central amygdala that are similar to the neuroadaptations that occur after chronic stress [55]. Further, research suggests that mood disorders and SUDs are both associated with deficits in the brain reward circuits and memory deficits [61]. Anhedonia and lack of motivation, both symptoms of depression have been linked to dysfunction of the dopaminergic system $[62,63]$. These findings may explain the high co-occurrence of mood disorders and alcohol use disorder (AUD).

Concerning PDs we found that all PDs were related to low levels of EC; none of the interaction terms were statistically significant.

ASPD is found to be highly associated with SUDs, mainly alcohol, cannabis and tobacco use and seems to reflect a general vulnerability to externalizing behaviors [64,65]. AUD is more severe in patients with a ASPD (earlier age of onset and more rapid progression to dependence [65]. Research also pointed out that "the traits of ASPD, such as deficits in executive function and response regulation as well as anxious-impulsive personality traits may represent endophenotypes associated with greater risk of developing cocaine and amphetamine use disorder" [65]. Studies have shown a prevalence between $30-50 \%$ for BPD and SUDs [36]. From a symptom perspective, Cluster B PD symptoms are uniquely associated with AUD [64].The link between the diagnoses SUDs and BPD seems to consist in impulsivity, emotional dysregulation and negative emotionality [65]. Symptoms of delusions of reference and social anxiety are in some studies linked to schizotypal traits (cluster A PD) that could predict cannabis consumption [65].

In sum, our study shows that low EC is involved in all clinical symptomatology and PDs in our sample of inpatients with SUDs; high BIS is related to internalizing symptomatology and cluster C PDs, and high BAS is related to hostility and the narcissistic and histrionic PD of Cluster B PDs. We only found a main effect of both regulative (EC) and reactive (BIS/BAS) temperament but not a moderating effect. As we were especially interested in the top-down regulation of psychopathology we did not include the interaction of BIS X BAS (the interplay between anxiety and reward). Our findings thus especially highlight the role of EC in the expression of psychopathology/comorbidity also in an adult sample of SUD patients of which is known they are already characterized by relatively low overall levels of self-control $[60,66]$.

The literature shows that also in a non-clinical sample adults with poor EC were more likely to report a higher number and greater severity of psychiatric symptoms [67]. In studies of executive functioning (EF) $[68,69]$, which is closely related to EC, there is evidence that impairments in cognitive control are related with almost all forms of psychopathology [68]. Several studies support the role of EC as a transdiagnostic dimension covering a continuum from normal mental health to psychiatric disorders/psychological problems cutting through the boundaries of both internalizing and externalizing disorders [9].

Therefore, knowing that EC plays a very important role in psychopathology, therapeutic interventions aiming to strengthen cognitive control/EC might result in better treatment outcomes in patients with SUD for both the addiction and comorbid psychopathology. Targeting the construct of EC in treatment may contribute to reductions across psychopathology and can be seen as a transdiagnostic approach which has the benefit to address several comorbidities at the same time. Cognitive-behavioral therapy (CBT) is the main method of 
psychotherapy generally accepted in the field of substance addiction and non-substance addiction and is designed to be applied to a variety of psychiatric disorders. Especially the "third wave therapies". e.g., mindfulnes-based interventions, Acceptance and Commitment Therapy (ACT), Dialectic Behavioral Therapy (DBT) can be seen as transdiagnostic treatments [70]. Further, cognitive training, e.g., Cognitive Bias Modification and training of working memory, has recently been applied in the treatment of for example, SUDs, mood and anxiety disorders [17,71-74]. However, in spite of some promising hypotheses and a limited number of positive outcome studies, the findings on the effectivity of cognitive training modules remain inconsistent.

Although this study has some strengths, especially in the large sample studied, some limitations should also be noted. First, the cross-sectional design used in the current study does not allow to infer causality. Second, we did not have a control group without SUD nor compared between different substances. Future research should thus include a control group and/or compare between different substances. Third, we only used self-report measures to assess temperament and severity of psychopathology, which increases the possibility of shared method variance inflating associations between the study variables. Future studies should thus combine self-report questionnaires assessing temperament with behavioral tasks. Further it seems important to investigate the influence of "age of onset" and "duration" of the substance abuse as it is known that chronic substance use further undermines the efficiency of control networks weakening the capacity for self-regulation.

To address the last two limitations, in our next study we shall combine self-report questionnaires assessing EC and behavioral tasks using the Cambridge Neuropsychological Test Automated Battery (CANTAB) and take into account the age of onset and duration of substance abuse.

\section{Conclusions}

Taken together, we found that low EC is involved in all clinical symptomatology and PDs in a sample of inpatients with SUDs. These findings are consistent with conceptualizations of EC as a major psychological dimension that may play a transdiagnostic role in shaping the risk for psychopathology. Therapeutic interventions aiming at strengthening cognitive control/EC can possibly result in better treatment outcomes for both the addiction and the comorbid psychopathology.

Supplementary Materials: The following supporting information can be downloaded at: https: / / www.mdpi.com/article/10.3390/jcm11030591/s1, Table S1: Type of Substance Used and Gender (12 categories).

Author Contributions: Conceptualization, E.S., L.C., E.D. and G.D.; data curation, E.S.; formal analysis, L.C., E.D. and E.S.; investigation, E.S., L.C. and E.D.; methodology, E.S., L.C., E.D. and G.D.; writing original draft, E.S.; writing review \& editing, E.S., G.D., E.D. and L.C. All authors have read and agreed to the published version of the manuscript.

Funding: This research was supported by Funding Brothers of Charity, Ghent, Belgium. The Funding had no role in the study design, collection, analysis or interpretation of the data, writing the manuscript, or the decision to submit the paper for publication.

Institutional Review Board Statement: Ethical review and approval were waived for this study due to the fact that the study protocol (a retrospective study) was based only on computerised self-report questionnaires and there were no health risks or other concerns associated with participating in this study.

Informed Consent Statement: Informed consent was obtained from all subjects involved in the study.

Data Availability Statement: Data are available from the authors upon request.

Conflicts of Interest: The authors declare no conflict of interest. 


\section{References}

1. Jacobi, F.; Wittchen, H.U.; Holting, C.; Hofler, M.; Pfister, H.; Muller, N.; Lieb, R. Prevalence, co-morbidity and correlates of mental disorders in the general population: Results from the German Health Interview and Examination Survey (GHS). Psychol. Med. 2004, 34, 597-611. [CrossRef] [PubMed]

2. Kessler, R.C.; Berglund, P.; Demler, O.; Jin, R.; Walters, E.E. Lifetime prevalence and age-of-onset distributions' of DSM-IV disorders in the national comorbidity survey replication. Arch. Gen. Psychiatry 2005, 62, 593-602. [CrossRef] [PubMed]

3. Whiteford, H.A.; Degenhardt, L.; Rehm, J.; Baxter, A.J.; Ferrari, A.J.; Erskine, H.E.; Charlson, F.J.; Norman, R.E.; Flaxman, A.D.; Johns, N.; et al. Global burden of disease attributable to mental and substance use disorders: Findings from the global burden of disease study. Lancet 2013, 382, 1575-1586. [CrossRef]

4. Koob, G.F.; Volkow, N.D. Neurocircuitry of addiction. Neuropsychopharmacology 2010, 35, 217-238. [CrossRef] [PubMed]

5. Yücel, M.; Oldenhof, E.; Ahmed, S.H.; Belin, D.; Billieux, J.; Bowden-Jones, H.; Carter, A.; Chamberlain, S.R.; Clark, L.; Connor, J.; et al. A transdiagnostic dimensional approach towards a neuropsychological assessment for addiction: An international Delphi consensus study. Addiction 2019, 114, 1095-1109. [CrossRef]

6. Bartoli, F.; Crocamo, C.; Biagi, E.; Di Carlo, F.; Parma, F.; Madeddu, F.; Capuzz, E.; Colmegna, F.; Clerici, M.; Carrà, G. Clinical utility of a single-item test for DSM-5 alcohol use disorder among outpatients with anxiety and depressive disorders. Drug Alcohol Depend. 2016, 1, 283-287. [CrossRef] [PubMed]

7. Ricci, V.; Ceci, F.; Di Carlo, F.; Lalli, A.; Ciavoni, L.; Mosca, A.; Sepede, G.; Salone, A.; Quattrone, D.; Fraticelli, S.; et al. Cannabis use disorder and dissociation: A report from a prospective first-episode psychosis study. Drug Alcohol Depend. 2021, 229 Pt A, 109118. [CrossRef]

8. Degenhardt, L.; Saha, S.; Lim, C.C.W.; Aguilar-Gaxiola, S.; Al-Hamzawi, A.; Alonso, J.; Andrade, L.H.; Bromet, E.J.; Bruffaerts, R.; Caldas-de-Almeida, J.M.; et al. WHO World Mental Health Survey Collaborators. The associations between psychotic experiences and substance use and substance use disorders: Findings from the World Health Organization World Mental Health surveys. Addiction 2018, 113, 924-934. [CrossRef] [PubMed]

9. Santens, E.; Claes, L.; Dierckx, E.; Dom, G. Effortful Control—A Transdiagnostic Dimension Underlying Internalizing and Externalizing Psychopathology. Neuropsychobiology 2020, 79, 255-269. [CrossRef] [PubMed]

10. Rothbart, M.K. Temperament in childhood: A framework. In Temperament in Childhood; Kohnstamm, G.A., Bates, J.E., Rothbart, M.K., Eds.; Wiley: New York, NY, USA, 1989; pp. 59-73.

11. Strack, F.; Deutsch, R. Reflective and impulsive determinants of social behavior. Pers. Soc. Psychol. Rev. 2004, 8, 220-247. [CrossRef] [PubMed]

12. Wiers, R.W.; Stacy, A.W. Implicit Cognition and Addiction. Curr. Dir. Psychol. Sci. 2006, 15, 292-296. [CrossRef]

13. Carver, C.S.; White, T.L. Behavioral Inhibition, Behavioral Activation, and Affective Responses to Impending Reward and Punishment: The BIS/BAS Scales. J. Pers. Soc. Psychol. 1994, 67, 319-333. [CrossRef]

14. Lonigan, C.J.; Vasey, M.W.; Phillips, B.M.; Hazen, R.A. Temperament, anxiety, and the processing of threat-relevant stimuli. J. Clin. Child Adolesc. Psychol. 2004, 33, 8-20. [CrossRef] [PubMed]

15. Nigg, J.T. Temperament and developmental psychopathology. J. Child Psychol. Psychiatry 2006, 47, 395-422. [CrossRef] [PubMed]

16. Nigg, J.T. Annual Research Review: On the relations among self-regulation, self-control, executive functioning, effortful control, cognitive control, impulsivity, risk-taking, and inhibition for developmental psychopathology. J. Child. Psychol. Psychiatry 2017, 58, 361-383. [CrossRef] [PubMed]

17. Rothbart, M.K.; Bate, J.E. Handbook of Child Psychology. Social, Emotional, Personality Development; Damon, W., Eisenberg, N., Eds.; Wiley: New York, NY, USA, 2006; Volume 3, pp. 99-166.

18. Bijttebier, P.; Beck, I.; Claes, L.; Vandereycken, W. Gray's Reinforcement Sensitivity Theory as a framework for research on personality-psychopathology associations. Clin. Psychol. Rev. 2009, 29, 421-430. [CrossRef] [PubMed]

19. Gray, J.A. The neuropsychology of temperament. In International Perspectives on Theory and Measurement: Perspectives on Individual Differences; Strelau, J., Angleitner, A., Eds.; Springer: Boston, MA, USA, 1991; pp. 105-128. [CrossRef]

20. Corr, P.J. Reinforcement sensitivity theory and personality. Neurosci. Biobehav. Rev. 2004, 28, 317-332. [CrossRef] [PubMed]

21. Gray, J.A.; McNaughton, N. The Neuropsychology of Anxiety: An Enquiry into the Functions of the Septo-Hippocampal System, 2nd ed.; Oxford University Press: Oxford, UK, 2000. [CrossRef]

22. Cooper, A.; Gomez, R.; Aucote, H. The Behavioural Inhibition System and Behavioural Approach System (BIS/BAS) Scales: Measurement and structural invariance across adults and adolescents. Pers. Individ. Differ. 2007, 43, 295-305. [CrossRef]

23. Oldehinkel, A.J.; Hartman, C.A.; Ferdinand, R.F.; Verhulst, F.C.; Ormel, J. Effortful control as modifier of the association between negative emotionality and adolescents' mental health problems. Dev. Psychopathol. 2007, 19, 523-539. [CrossRef]

24. Franken, I.H. Behavioral approach system (BAS) sensitivity predicts alcohol craving. Pers. Individ. Differ. 2002, 32, 349-355. [CrossRef]

25. Kambouropoulos, N.; Staiger, P.K. The influence of sensitivity to reward on reactivity to alcohol-related cues. Addiction 2001, 96, 1175-1185. [CrossRef] [PubMed]

26. Kambouropoulos, N.; Staiger, P.K. Reactivity to alcohol-related cues: Relationship among cue type, motivational processes, and personality. Psychol. Addict. Behav. 2004, 18, 275-283. [CrossRef] [PubMed]

27. Verdejo-Garcia, A.; Garcia-Fernandez, G.; Dom, G. Cognition and addiction. Dialogues Clin. Neurosci. 2019, 21, 281-290. [PubMed] 
28. Cheetham, A.; Allen, N.B.; Yücel, M.; Lubman, D.I. The role of affective dysregulation in drug addiction. Clin. Psychol. Rev. 2010, 30, 621-634. [CrossRef] [PubMed]

29. Peeters, M.; Oldehinkel, T.; Vollebergh, W. Behavioral Control and Reward Sensitivity in Adolescents' Risk Taking Behavior: A Longitudinal TRAILS Study. Front. Psychol. 2017, 8, 231. [CrossRef] [PubMed]

30. Nigg, J.T.; Glass, J.M.; Wong, M.M.; Poon, E.; Jester, J.M.; Fitzgerald, H.E.; Puttler, L.I.; Adams, K.M.; Zucker, R.A. Neuropsychological executive functioning in children at elevated risk for alcoholism: Findings in early adolescence. J. Abnorm. Psychol. 2004, 113, 302-314. [CrossRef]

31. Wong, M.M.; Rowland, S.E. Self-determination and substance use: Is effortful control a mediator? Alcohol Clin. Exp. Res. 2013, 37, 1040-1047. [CrossRef]

32. Koob, G.F.; Volkow, N.D. Neurobiology of addiction: A neurocircuitry analysis. Lancet Psychiatry 2016, 3, 760-773. [CrossRef]

33. Santens, E.; Claes, L.; Dierckx, E.; Luyckx, K.; Peuskens, H.; Dom, G. Personality profiles in substance use disorders: Do they differ in clinical symptomatology, personality disorders and coping? Pers. Individ. Dif. 2018, 131, 61-66. [CrossRef]

34. McHugh, R.K.; Weiss, R.D. Alcohol Use Disorder and Depressive Disorders. Alcohol Res. 2019, 40. [CrossRef]

35. Koudys, J.A.; Ruocco, A.C. A neurocognitive model of the comorbidity of substance use and personality disorders. In Cognition and Addiction, A Researcher's Guide from Mechanisms towards Interventions, 1st ed.; Verdejo-Garcia, A., Ed.; Academic Press: Cambridge, MA, USA; Elsevier: Amsterdam, The Netherlands, 2020; pp. 79-89.

36. Trull, T.J.; Tomko, R.L.; Brown, W.C.; Scheiderer, E.M. Borderline personality disorder in 3-D: Dimensions, symptoms, and measurement challenges. Soc. Personal. Psychol. Compass 2010, 4, 1057-1069. [CrossRef]

37. Alonso, J.; Angermeyer, M.C.; Bernert, S.; Bruffaerts, R.; Brugha, T.S.; Bryson, H.; de Girolamo, G.G.; Demyttenaere, K.; Gasquet, I.; Haro, J.M.; et al. Prevalence of mental disorders in Europe: Results from the European Study of the Epidemiology of Mental Disorders (ESEMeD) project. Acta Psychiatr. Scand. Suppl. 2004, 420, 21-27. [CrossRef]

38. EMCDDA (European Monitoring Centre for Drugs and Drug Addiction). Comorbidity of Substance Use and Mental Disorders in Europe, EMCDDA Insights; Publications Office of the European Union: Luxembourg, 2015.

39. Clements, A.D.; Bailey, B.A. The relationship between temperament and anxiety: Phase I in the development of a risk screening model to predict stress-related health problems. J. Health. Psychol. 2010, 15, 515-525. [CrossRef] [PubMed]

40. Dinovo, S.A.; Vasey, M.W. Reactive and self-regulatory dimensions of temperament: Interactive relations with symptoms of general distress and anhedonia. J. Res. Pers. 2011, 45, 430-440. [CrossRef] [PubMed]

41. Tortella-Feliu, M.; Aguayo, B.; Sesé, A.; Morillas-Romero, A.; Balle, M.; Gelabert, J.M.; Bornas, X.; Llabrés, J. Effects of temperament and emotion regulation styles in determining negative emotional states. Actas. Esp. Psiquiatr. 2012, 40, 315-322. [PubMed]

42. Xie, J.; Fang, P.; Zhang, Z.; Luo, R.; Dai, B. Behavioral inhibition/activation systems and depression among females with substance use disorder: The mediating role of intolerance of uncertainty and anhedonia. Front. Psychiatry 2021, 12, 64482. [CrossRef] [PubMed]

43. American Psychiatric Association. Diagnostic and Statistical Manual of Mental Disorders (DSM-5 $\left.{ }^{\circledR}\right)$; American Psychiatric Pub.: Washington, DC, USA, 2013.

44. Claes, L.; Vertommen, S.; Smits, D.; Bijttebier, P. Emotional reactivity and self-regulation in relation to personality disorders. Pers. Individ. Dif. 2009, 47, 948-953. [CrossRef]

45. De Panfilis, C.; Riva, P.; Preti, E.; Cabrino, C.; Marchesi, C. When social inclusion is not enough: Implicit expectations of extreme inclusion in borderline personality disorder. Personal. Disord. 2015, 6, 301-309. [CrossRef] [PubMed]

46. Ross, S.R.; Keiser, H.N.; Strong, J.; Webb, C.M. Reinforcement sensitivity theory and symptoms of personality disorder: Specificity of the BIS in Cluster C and BAS in Cluster B. Pers. Individ. Dif. 2013, 54, 289-293. [CrossRef]

47. Korsgaard, H.O.; Torgersen, S.; Wentzel-Larsen, T.; Ulberg, R. Substance abuse and personality disorder comorbidity in adolescent outpatients: Are girls more severely ill than boys? Child Adolesc. Psychiatry Ment. Health. 2016, 10. [CrossRef]

48. Trull, T.J.; Freeman, L.K.; Vebares, T.J.; Choate, A.M.; Helle, A.C.; Wycoff, A.M. Borderline personality disorder and substance use disorders: An updated review. Borderline Personal Disord. Emot. Dysregul. 2018, 5, 15. [CrossRef] [PubMed]

49. Evans, D.E.; Rothbart, K.E. Developing a model for adult temperament. J. Res. Pers. 2007, 41, 868-888. [CrossRef]

50. Verstraeten, K.; Vasey, M.W.; Claes, L.; Bijttebier, P. The assessment of effortful control in childhood: Questionnaires and the Test of Everyday Attention for Children compared. Pers. Individ. Dif. 2010, 48, 59-65. [CrossRef]

51. Arrindell, W.A.; Ettema, J.H. Symptom checklist (SCL-90). In Handleiding bij een Multidimensionele Psychopathologie-Indicator; Swets Test Publishers: Lisse, The Netherlands, 2003.

52. Benjamin, A.B.; Mossman, D.; Graves, N.S.; Sanders, R.D. Tests of a symptom checklist to screen for comorbid psychiatric disorders in alcoholism. Compr. Psychiatry 2006, 47, 227-233. [CrossRef] [PubMed]

53. Schotte, C.K.; De Doncker, D. ADP-IV Questionnaire: Manual and Norms; University Hospital Antwerp: Antwerp, Belgium, 1994.

54. Tarter, R.E.; Kirisci, L. Validity of the Drug Use Screening Inventory for predicting DSM-III-R substance use disorder. J. Child Adolesc. Subst. Abus. 2001, 10, 45-53. [CrossRef]

55. Anker, J.J.; Kushner, M.G. Co-Occurring Alcohol Use Disorder and Anxiety: Bridging Psychiatric, Psychological, and Neurobiological Perspectives. Alcohol Res. 2019, 40. [CrossRef] [PubMed]

56. Lai, H.M.; Cleary, M.; Sitharthan, T.; Hunt, G.E. Prevalence of comorbid substance use, anxiety and mood disorders in epidemiological surveys, 1990-2014: A systematic review and meta-analysis. Drug Alcohol Depend. 2015, 154, 1-13. [CrossRef] 
57. Gómez-Coronado, N.; Sethi, R.; Bortolasci, C.C.; Arancini, L.; Berk, M.; Dodd, S. A review of the neurobiological underpinning of comorbid substance use and mood disorders. J. Affect. Disord. 2018, 241, 388-401. [CrossRef]

58. Kushner, M.G.; Sher, K.J.; Wood, M.D.; Wood, P.K. Anxiety and drinking behavior: Moderating effects of tension-reduction alcohol outcome expectancies. Alcohol Clin. Exper. Res. 1994, 18, 852-860. [CrossRef]

59. Crum, R.M.; Mojtabai, R.; Lazareck, S.; Bolton, J.M.; Robinson, J.; Sareen, J.; Green, K.M.; Stuart, E.A.; La Flair, L.; Alvanzo, A.A.; et al. A prospective assessment of reports of drinking to self-medicate mood symptoms with the incidence and persistence of alcohol dependence. JAMA Psychiatry 2013, 70, 718-726. [CrossRef]

60. Volkow, N.D.; Koob, G.F.; McLellan, A.T. Neurobiologic advances from the brain disease model of addiction. N. Eng. J. Med. 2016, 374, 363-371. [CrossRef] [PubMed]

61. Russo, S.J.; Nestler, E.J. The brain reward circuitry in mood disorders. Nat. Rev. Neurosci. 2013, 14, 609-625. [CrossRef] [PubMed]

62. Belujon, P.; Grace, A.A. Dopamine System Dysregulation in Major Depressive Disorders. Int. J. Neuropsychopharmacol. 2017, 20, 1036-1046. [CrossRef] [PubMed]

63. Destoop, M.; Morrens, M.; Coppens, V.; Dom, G. Addiction, Anhedonia, and Comorbid Mood Disorder. A Narrative Review. Front. Psychiatry 2019, 10, 311. [CrossRef] [PubMed]

64. Trull, T.J.; Waudby, C.J.; Sher, K.J. Alcohol, tobacco, and drug use disorders and personality disorder symptoms. Exp. Clin. Psychopharmacol. 2004, 12, 65. [CrossRef] [PubMed]

65. Szerman, N.; Peris, L. Personality disorders and addiction disorders. In Textbook of Addiction Treatment: International Perspectives; El Guebaly, N., Carrà, G., Galanter, M., Baldaccino, A.M., Eds.; Springer: Milan, Italy, 2015; pp. 2063-2082. [CrossRef]

66. Corbin, W.R.; Papova, A.; Morean, M.E.; O'Malley, S.S.; Krishnan-Sarin, S.; Abi-Dargham, A.; Anticevic, A.; Pearlson, G.; Petrakis, I.; Pittman, B.P.; et al. Integrating acquired preparedness and dual process models of risk for heavy drinking and related problems. Psychol. Addict. Behav. 2015, 29, 864-874. [CrossRef]

67. De Panfilis, C.; Meehan, K.B.; Cain, N.M.; Clarkin, J.F. The relationship between effortful control, current psychopathology and interpersonal difficulties in adulthood. Compr. Psychiatry 2013, 54, 454-461. [CrossRef]

68. Snyder, H.R.; Miyake, A.; Hankin, B.L. Advancing understanding of executive function impairments and psychopathology: Bridging the gap between clinical and cognitive approaches. Front Psychol. 2015, 6, 328. [CrossRef]

69. McTeague, L.M.; Huemer, J.; Carreon, D.M.; Jiang, Y.; Eickhoff, S.B.; Etkin, A. Identification of Common Neural Circuit Disruptions in Cognitive Control Across Psychiatric Disorders. Am. J. Psychiatry 2017, 174, 676-685. [CrossRef]

70. Schaeuffele, C.; Schulz, A.; Knaevelsrud, C.; Renneberg, B.; Boettcher, J. CBT at the Crossroads: The Rise of Transdiagnostic Treatments. J. Cogn. Ther. 2021, 14, 86-113. [CrossRef]

71. Wiers, R.W.; Gladwin, T.E.; Hofmann, W.; Salemink, E.; Ridderinkhof, K.R. Cognitive Bias Modification and Cognitive Control Training in Addiction and Related Psychopathology: Mechanisms, Clinical Perspectives, and Ways Forward. Clin. Psychol. Sci. 2013, 1, 192-212. [CrossRef]

72. Keshavan, M.S.; Vinogradov, S.; Rumsey, J.; Sherrill, J.; Wagner, A. Cognitive training in mental disorders: Update and future directions. Am. J. Psychiatry 2014, 171, 510-522. [CrossRef] [PubMed]

73. Fodor, L.A.; Georgescu, R.; Cuijpers, P.; Szamoskozi, Ş.; David, D.; Furukawa, T.A.; Cristea, I.A. Efficacy of cognitive bias modification interventions in anxiety and depressive disorders: A systematic review and network meta-analysis. Lancet Psychiatry 2020, 7, 506-514. [CrossRef]

74. Verdejo-Garcia, A. Cognitive training for substance use disorders: Neuroscientific mechanisms. Neurosci. Biobehav. Rev. 2016, 68, 270-281. [CrossRef] 